\title{
INTERFACES DA HISTÓRIA DA ENFERMAGEM: UMA POTENCIAL AGENDA DE PESQUISA
}

\author{
Interfaces of the History of Nursing: \\ A potential agenda of research \\ Interfazes de la Historia de Enfermería: \\ Una potencial agenda de investigación
}

André de Faria Pereira Neto

\begin{abstract}
Resumo
Durante o século XX, o conhecimento histórico deixou de apresentar-se como uma relação de datas e fatos marcantes, colocados em ordem cronológica, para assumir uma feição crítica que parte de problemas do presente e busca analisá-los no passado. A História da Saúde passou igualmente por esta mudança. 0 objetivo deste artigo é apresentar, de forma sumária, alguns elementos presentes no debate historiográfico contemporâneo sobre História da Saúde, da Ciência, das Mulheres e das Profissões. A escolha destas áreas se justifica na medida em que elas são interfaces potenciais para a escrita da História da Enfermagem. Cada uma delas, da sua maneira, contribui para valorizar esta profissão, pois resgata sua memória e divulga sua história: partes imprescindíveis para a construção da identidade de qualquer profissão. Com isso, pretendemos sugerir que a produção histórica em Enfermagem leve em consideração esta controvérsia historiográfica e se inscreva nela de forma consciente e qualificada.
\end{abstract}

Palavras-chave: História da Enfermagem. História. Saúde.

\begin{abstract}
During the $20^{\text {th }}$ Century, historical knowledge ceased to present itself solely as a chronological list of dates and facts. Rather, it developed into a critical feature that detaches from problems of the present while attempting to analyze the past. The history of health also suffered from the same transformation. The purpose of this article is to summarize some current elements of the contemporary historiographical debate surrounding the History of Health, Science, Women, and Professions. The choice of these areas is justified because of their potential as a collective medium for writing about the history of nursing. It revitalizes and publicizes its history - indispensable components for the construction of identity of any profession. In this way, we invite scholars of the History of Nursing to take into consideration this controversial historiography and introduce them into the discussion in a conscientious and qualified manner.
\end{abstract}

\section{Resumen}

Durante el siglo XX, el conocimiento histórico terminó por presentarse en forma de simples hechos con sus correspondientes fechas. Se desarrolló como una característica crítica que se separa de los problemas del presente, al mismo tiempo que intenta analizar el pasado. La historia de la salud también fué sometida a esta transformación. El propósito de este artículo es sumar varios elementos del debate histográfico contemporáneo sobre la história de la salud, la ciéncia, la mujer, y las profesiones. La selección de estas áreas es justificada por su potencial como un medio colaborativo para escribir sobre la historia de la enfermería. Revitaliza y publica la historia de los componentes indispensables para la construcción de identidad de cualquier profesión. Es en esta manera que invitamos a eruditos historiadores de enfermeria a considerar esta histografía controversial y los invitamos también a entrar en una discusión sobre el tema en una manera concienzuda y calificada.
Keywords:

History of Nursing. History. Health.
Palabras clave:

Historia de Enfermería. Historia. Salud. 


\section{INTRODUÇÃO}

A visão tradicional dos estudos históricos está associada à descrição incansável de fatos e personagens. Neste contexto, alguns 'vultos' da História foram eleitos e muitas datas e monumentos foram construídos para fazer lembrar ao cidadão comum 0 que não devia ou não podia ser esquecido. Apesar de proclamar-se isenta e avessa à política, esta maneira de escrever História detinha forte conotação ideológica. 0 denominado 'historicismo', que fez com que a História fosse pautada na descrição do acontecimento, dominou e ainda domina, em grande parte, a cena historiográfica. Há pelo menos cinqüenta anos ela tem sido criticada. 0 movimento historiográfico conhecido como 'Escola dos Annales', ou 'Nova História', na França, começou a produzir, sobretudo no pósSegunda Guerra Mundial, um inventário de inovações que influenciam, ainda hoje, a produção do setor (Burke $\left.{ }^{1}\right)$. Aos poucos, a maneira de escrever História passou a incluir novos problemas, abordagens e objetos (Le Goff et al..$^{2}$ ). Estas três dimensões atribuídas aos estudos históricos são dignas de nota. A História passou a ter problemas e, como qualquer ciência, merece partir de questões. Para desenvolver uma pesquisa histórica, o pesquisador contemporâneo apresenta de forma clara, precisa e justificável qual é seu problema, ou sua questão norteadora. Este problema motiva o investigador a realizar sua pesquisa e o leitor a tomar contato com seus resultados. Além disso, os estudos históricos passaram a ter diferentes abordagens. Neste sentido, as abordagens permitem que um mesmo problema possa ser observado de ângulos distintos, com ferramentas ou instrumentos de pesquisa específicos. Nos últimos anos, novas abordagens ampliaram o diálogo da História com as demais Ciências Sociais. Um diálogo, considerado até então prejudicial, passou a ser visto como uma crescente possibilidade inovadora para o campo. Finalmente, o movimento da 'Escola dos Annales' introduziu novos objetos de estudo. Para os historiadores tradicionais, os objetos dignos de estudo eram as efemérides sociais como as grandes datas nacionais. 0 historicismo transformou os heróis e seus feitos em incontáveis páginas de pesquisa. Neste sentido, os detalhes da vida palaciana, em suas minúcias, fez 0 deleite das côrtes e de seus inventores: os historiadores. Com a 'Nova História', outros objetos passaram ser tema de pesquisa. A mulher, a fome, os hábitos privados e as festas populares passaram a integrar a agenda de pesquisa dos historiadores modernos.

Além disso, metodologicamente a 'Nova História' criticava a soberania do documento escrito. Para 0 historicismo, o documento escrito era uma prova incontestável do vivido e só ele poderia ter o estatuto de documento. Discordando desta visão, os historiadores franceses defendiam a idéia de que 0 documento, qualquer que seja ele, não é fonte imanente da verdade. Ele é construído por pessoas e instituições e sobrevive ao tempo. Por esta razão, merece sofrer uma crítica por quem o utiliza. 0 documento escrito, ou não, passou a ser visto como fruto de uma época. Com a 'Nova História', utensílios domésticos, depoimentos orais, fotografias e imagens passaram a ter o mesmo estatuto de cientificidade que o documento escrito. 0 uso de novos documentos, temas e objetos deu uma outra dimensão aos estudos históricos. No lugar de investigar a vida dos reis, o historiador passou a se interessar pela vida do camponês. 0 homem comum passou a tomar o centro da cena. Temas pouco palpáveis e essencialmente interdisciplinares, como a morte, passaram a ser privilegiados. A saúde como objeto para a História pode ser vista, portanto, como parte do processo mais amplo de reformulação dos estudos históricos, iniciado com a 'Escola dos Annales' e que hoje se transformou em inúmeras correntes historiográficas (Cardoso et al. ${ }^{3}$ ).

No Brasil, as obras que, pela primeira vez, aproximaram a História e a Saúde obedeceram, em linhas gerais, a mesma matriz historicista criticada pelos franceses seguidores da 'Escola dos Annales'. Como exemplo de estudos de História da Medicina de forte conotação factual, podemos citar os livros de Santos Filho ${ }^{4}$, entre outros. Em linhas gerais, estes trabalhos apresentam uma história regida por uma periodização em marcha evolutiva, reunindo documentos oficiais ou, como um dos títulos anuncia, descrevendo figuras e fatos da Medicina no Brasil. Assim, até meados dos anos 1970, o saber histórico sobre saúde era tratado como uma sucessão de datas e nomes considerados importantes. Os autores estabeleciam, entre estes fatos e datas, relações mecânicas de causa e efeito, que muitas vezes reafirmavam a providência do Estado como agente capaz de estabelecer a ordem, independente dos interesses institucionais ou sociais.

A influência do pensamento e da obra de Foucault ${ }^{5}$, particularmente do livro 'Nascimento da Clínica', se fez sentir no Brasil do final dos anos 1970 e início dos anos 1980. Esta influência foi tão forte que chegou a interferir no curso da história da relação entre a História e as ciências da saúde. Nesta época, Machado et al. ${ }^{6}$ e Luz ${ }^{7}$ publicaram respectivamente seus livros onde 0 desenvolvimento da medicina no Brasil foi visto como parte integrante do processo de expansão do sistema capitalista, e os médicos, como 'intelectuais orgânicos' 
do Estado. Com influências e preocupações semelhantes, alguns anos depois, Costa ${ }^{8}$ desenvolveu um estudo em que as táticas médico-higiênicas presentes na intimidade da família do século XIX interferiram em seu equilíbrio e contribuíram para a afirmação da 'ordem burguesa'. Estes três trabalhos não julgaram a cientificidade da medicina. Ela foi vista como um saber que estava relacionado necessariamente com um novo tipo de poder.

Diante do que vinha sendo publicado, podemos afirmar que estes três trabalhos realizaram uma ruptura epistemológica na produção historiográfica sobre a relação entre a História e a Saúde, no Brasil. Filhos de seu tempo, estes trabalhos seguiram, sobretudo, vertentes marxistas e gramscianas das quais Foucault era um dos seus seguidores e inovadores. A partir de então, outros estudos procuraram aproximar a História e a Saúde de forma diferente daquela adotada pelo historicismo. Muitos estudos posteriores fizeram destas três obras uma referência obrigatória. 0 reconhecimento de que estes trabalhos foram inovadores não impediu que fossem sendo elaboradas novas possibilidades de investigação. Alguns exemplificam que é possível e desejável que o mesmo objeto seja analisado segundo diferentes problemas e abordagens. Assim, apesar de o objeto ser o mesmo, os resultados da pesquisa podem ser distintos. Esta é uma das inovações que a 'Escola dos Annales' introduziu na escrita da história de nosso tempo e que já gerou seus frutos em estudos de História da Saúde no Brasil. Estes são apenas alguns exemplos do vigor que domina atualmente este campo de estudo. 0 'Programa de Pós-Graduação em História das Ciências da Saúde' da Casa de Oswaldo Cruz tem produzido Dissertações de Mestrado e Teses de Doutorado com o mesmo intuito. A Revista 'História, Ciências, Saúde - Manguinhos' tem se revelado como um importante depositário de incontáveis trabalhos de caráter relevante e inovador nesta área.

Ao se escrever História da Enfermagem, a controvérsia sinalizada anteriormente poderia ser levada em consideração. Infelizmente, muitos trabalhos históricos, feitos atualmente com dedicação e cuidado, continuam sob a influência do historicismo. Continuam descrevendo exaustivamente fatos e personagens que marcaram a História da Enfermagem. Temos a impressão de que muitas das enfermeiras que pesquisam e escrevem História da Enfermagem desconhecem a controvérsia existente entre o historicismo, a Escola dos Annales e as diversas correntes de pensamento historiográfico contemporâneo. Por desconhecerem esta controvérsia, algumas enfermeiras acabam escrevendo uma história convencional, cronológica e evolutiva com aquela que foi criticada pelos franceses da Escola dos Annales.

Para que a História da Enfermagem seja escrita de maneira distinta da convencional, sugerimos que ela seja inserida em outros campos do conhecimento vizinhos, com os quais já estabelece intensa relação. Esta interfaces podem ajudar as pesquisadoras a inserir seu trabalho em um conjunto de problemáticas e autores particulares. São interfaces potenciais na medida em que elas abrem um leque de possibilidades de investigação. Elas são também potenciais, pois guardam grande capacidade de modificar a forma como vem sendo escrita a História da Enfermagem em nosso país.

Existem pelo menos três possibilidades, três interfaces, de abordagem histórica para a Enfermagem. Um seria observar a Enfermagem como uma ciência. Desta forma, uma interface possível seria com a História das Ciências, suas preocupações e questões particulares. Outra seria observar a Enfermagem como uma atividade desenvolvida, sobretudo, por mulheres. Sua história pode ser vista como integrante da História das Mulheres. Finalmente, a Enfermagem, enquanto atividade presente e marcante no mercado de trabalho, poderia ser vista como mais uma profissão da saúde. A História da Enfermagem poderia ser inserida neste como uma parte relevante na história das profissões de saúde. Em cada um dos casos, existem controvérsias teóricas e metodológicas próprias. A escolha destas três áreas se justifica na medida em que elas são interfaces potenciais para uma nova escrita da História da Enfermagem. No nosso entender, elas poderiam ser levadas em consideração quando se pensa em desenvolver uma agenda de pesquisa em História da Enfermagem.

0 objetivo deste artigo é apresentar de forma sumária, alguns elementos presentes no debate historiográfico contemporâneo sobre História da Ciência, das Mulheres e das Profissões. Metodologicamente, analisaremos algumas das principais obras e idéias presentes em cada um destes três campos de pesquisa. Nossa fonte de pesquisa serão, portanto, livros e artigos publicados na História das Ciências, das Mulheres e das Profissões.

Insistimos que os estudos históricos em Enfermagem têm uma importância vital no momento atual. Eles podem contribui para valorizar, ainda mais, esta profissão, pois resgatam sua memória e divulgam sua história: partes imprescindíveis para a construção da identidade de qualquer profissão. Com isso, ousamos sugerir que a produção histórica em Enfermagem leve em consideração esta controvérsia historiográfica e se inscreva nela de forma consciente e qualificada. 


\section{A HISTÓRIA (DA CIÊNCIA) DA ENFERMAGEM}

A área da História da Ciência, por exemplo, reúne profissionais de diferentes formações universitárias, mas com a mesma preocupação: desenvolver projetos de pesquisa sobre a epistemologia das ciências. Assim físicos, matemáticos, geólogos, engenheiros, médicos, biólogos, historiadores e sociólogos, entre outros, resgatam os fenômenos científicos ou tecnológicos atribuindo-lhes perspectiva histórica. Alguns apresentam estudos mais internalistas enquanto outros se mostram externalistas. No primeiro caso, os estudiosos analisam as descobertas científicas como fenômenos restritos ao laboratório e ao âmbito da ciência. No segundo, a ênfase é dada à sociedade. Ela é vista como a principal responsável pelo sucesso ou fracasso de uma determinada pesquisa ou descoberta.

Em seus estudos, Latour ${ }^{9}$ condenou tanto os internalistas quanto os externalistas. A crítica que fez aos internalistas relaciona-se ao fato de pretenderem analisar o processo de produção científica como sendo exclusivamente fruto do trabalho de pesquisadores, construindo uma imagem idílica, pura e desinteressada da atividade científica. Quando se fala de ciência, os leitores, convencidos por esta perspectiva, pensam logo em sábios célebres, em disciplinas e universidades com prestígio que produzem novas idéias e conhecimentos completamente dissociados do que se passa na sociedade. A crítica que fez aos externalistas vinculase ao fato de conceberem o trabalho científico como sendo fruto exclusivo das determinações sociais, políticas e econômicas que ele sofre durante sua elaboração. Os externalistas, no seu entender, erram quando cuidadosamente negligenciam a análise dos conteúdos das disciplinas e a realidade dos laboratórios. Para ele, um estudo na área da História da Ciência precisa combinar as duas perspectivas, verificando, em cada caso, o peso relativo que cada uma tem. Os estudos históricos da Enfermagem que se inscreverem na área da História das Ciências precisam levar em consideração as controvérsias sinalizadas por Latour.

Kuhn ${ }^{10}$ é também um dos mais célebres autores internacionais nesta área. Sua análise trouxe à tona o uso dos conceitos como 'paradigma' e 'comunidade científica', aplicado à história do fazer científico. Para ele, paradigma é aquilo que os membros de uma comunidade partilham. Na comunidade científica, os homens partilham um paradigma comum. Assim, para Kuhn 22:209, a comunidade científica pode repudiar um antigo paradigma, "renunciando simultaneamente à maioria dos livros e artigos que o corporificam, deixando de considerá-los como objeto adequado ao escrutínio científico". Este foi o caso, por exemplo, da matriz historicista que no campo da História deixou de ser o 'paradigma' do conhecimento.

Esta parece ser uma outra possibilidade de pesquisa para quem pretende trabalhar a História da Ciência da Enfermagem: resgatar o paradigma que tenha influenciado a Ciência da Enfermagem em determinada época e que possa ser revelado em livros e artigos. A base cognitiva da Enfermagem, e suas transformações ao longo do tempo, poderia compor uma agenda que se aproximasse da visão proposta por Kuhn.

A obra célebre de Schwartzman ${ }^{11}$, com forte inspiração na visão de Kuhn, analisou a formação da comunidade científica no Brasil, deixando de dedicar atenção à comunidade de enfermagem. Independente das razões que levaram este autor a não inserir a Enfermagem entre as ciências que construíram sua própria comunidade, a enfermeiras interessadas na História da Ciência da Enfermagem poderiam, inspirando-se nas preocupações e procedimentos metodológicos sugeridos por Schwartzman, analisar a criação de suas disciplinas e instituições científicas. Uma agenda de pesquisa comparando a História da Ciência da Enfermagem e as diferentes dinâmicas institucionais, em contextos históricos e culturais diversos, poderia evidenciar as similitudes e especificidades de um processo que é, ao mesmo tempo, comum e singular.

Uma outra possibilidade, sempre enriquecedora, pode ser desenvolvida na área das biografias e trajetórias profissionais de cientistas. As histórias de vida dos cientistas recuperam a dimensão humana, muitas vezes negligenciada, desta prática. A face pública e a privada de sua vida precisariam estar, de alguma forma, associadas. Em geral, as biografias de uma autoridade científica conhecida apresentam uma relação das grandes ações e descobrimentos $\left(\right.$ Roberts $\left.{ }^{12}\right)$. Este relato é extremamente descritivo e cronológico. A influência da escola historicista aparece mais uma vez. Uma possibilidade de não cair nesta vala comum a tantos estudos biográficos seria recuperar a vida íntima e singular de um indivíduo inserindo-a nas circunstâncias históricas e sociais em que estava inscrito. Com isso, poderia ser verificado em que medida a combinação deste interesses influenciou as decisões que foram tomadas.

As Bibliotecas Virtuais de Notáveis em Ciência e Tecnologia, disponíveis no site do Instituto Brasileiro de Informação em Ciência e Tecnologia, oferecem um conjunto de cerca de setenta Bibliotecas Virtuais 
contendo textos biográficos de diversos cientistas das ciências exatas, biológicas, humanas e sociais, da saúde e da terra. Neste conjunto, não há menção a uma só enfermeira. Uma agenda de pesquisa recuperando a trajetória profissional de enfermeiras notáveis poderia compor este quadro incompleto.

Uma análise comparativa sobre trajetórias de profissionais latino-americanas que viveram a mesma época, em realidades geográficas e sóciohistóricas diferentes, poderia abrir uma nova perspectiva de investigação.

Vejamos, a seguir, como a História das Mulheres pode servir de interface para a História da Enfermagem: que autores têm se destacado, que questões têm levantado e como a História da Enfermagem pode se inserir neste contexto.

\section{A HISTÓRIA (DA MULHER) NA ENFERMAGEM}

A mulher tornou-se objeto para a História dentro do processo de busca de novos objetos, provocada pelo movimento da historiografia da 'Escola dos Annales' analisado anteriormente. Georges Duby e Michelle Perrot ${ }^{13}$ são reconhecidos internacionalmente como os fundadores deste campo de pesquisa por terem publicado uma obra monumental em cinco volumes, no início da década de 1990. Este livro foi um dos que abriu este campo de investigação, atribuindo à mulher uma notoriedade científica na História nunca antes vista. Com o passar do tempo, diferentes autores de diversas partes do mundo procuraram pesquisar, escrever e publicar histórias de mulheres em seus próprios países. No Brasil, esforço pioneiro foi empreendido por Bresciani, que, seguindo as pistas sugeridas pelos dois franceses mencionados anteriormente, resolveu colocar os excluídos da história no centro da cena. Bresciani ${ }^{14}$ organizou uma coletânea de artigos enfocando a mulher no espaço público. Neste caso, pode-se verificar que a pesquisa histórica sobre mulher sofreu forte inspiração, inicialmente, marxista e foucaultiana. Assim, a gênese deste campo de estudos pode ser inserida no grande processo de alargamento da perspectiva histórica, que inclui novos objetos e ao mesmo tempo passa a abordá-los de maneira não historicista, optando, nos anos 1980, por um corte influenciado pelo estruturalismo. Este fenômeno pode ser observado tanto nos estudos históricos pioneiros sobre a mulher quanto sobre a saúde, conforme analisamos anteriormente.

Del Priori ${ }^{15}$ seguiu uma perspectiva historiográfica mais próxima à História das Mentalidades, fazendo da mulher seu objeto preferencial de análise. Mais uma vez a explicação para as novas correntes historiográficas está relacionada à 'Escola dos Annales'. Seus fundadores alargam as fronteiras da História Social ao domínio das representações coletivas. A preocupação deles era resgatar as maneiras de sentir e de pensar da sociedade em diferentes épocas históricas. Com estes intelectuais, os estudos históricos passaram a ser cada vez mais consagrados a uma esfera residual do passado e fizeram com que o social e o cultural aparecessem intimamente interligados.

A Enfermagem constituiu-se, desde sua gênese, em um campo de saber e de prática com hegemonia feminina. Estudar a História da Enfermagem é, em certa medida, estudar a História da Mulher. Os estudos históricos em Enfermagem tem todas as condições de se inscrever nesta controvérsia historiográfica.

\section{A HISTÓRIA (DA PROFISSÃO) DE ENFERMAGEM}

Quando usamos o conceito profissão, amparamo-nos sobretudo em Freidson ${ }^{16}$, que define a profissão como uma ocupação com prestígio e poder especial, que adquire por meios políticos, culturais e ideológicos, extraordinária autoridade cognitiva e normativa. Ele publicou diversos trabalhos onde a profissão se tornou um objeto de estudo sociológico e histórico. Neste sentido, este livro é considerado "de fato, a sua obra seminal, o seu verdadeiro clássico" (Barbosa ${ }^{17: 595}$ ). Nele 0 autor condena a idéia de que o treinamento altamente especializado e prolongado seja a principal característica de uma profissão. Em linhas gerais, podemos dizer que uma profissão, do ponto de vista sociológico, comporta certas características que a singularizam dentre as atividades do mundo do trabalho. Características particulares, que podem ser tratadas de modo integrado.

0 conhecimento profissional, por exemplo, para ser base de sua autoridade, precisa deter pelo menos três características: ser complexo e incompreensível por leigos e ser institucionalizado em estabelecimentos de ensino. Ele precisa ser ainda, e sobretudo, aplicável. Assim, a profissão procurará resolver problemas tidos como relevantes pela sociedade. A profissão precisa fazer com que seu conhecimento aplicado seja reconhecido como imprescindível e aceito culturalmente por seus consumidores. A lei, apesar de fundamental, não é suficiente para definir concretamente as fronteiras de competência. Com o domínio do conhecimento e a definição formal de sua competência, a profissão satisfaz uma condição necessária, mas não suficiente, para reivindicar exclusiva jurisdição acerca de determinada atividade. Ela também procura se firmar no mercado de trabalho. 
A profissão faz de tudo para conquistar e preservar sua autonomia técnica e econômica no mercado de trabalho. A primeira diz respeito à natureza da atividade e às possíveis interferências externas sobre sua liberdade. Ou seja, a autonomia técnica se refere à maneira com que o trabalho profissional é feito. Esta dimensão da autonomia pressupõe que o profissional seja capaz de invalidar o serviço do leigo, comprometendo-se com a organização de efetivo controle de admissão. A segunda relaciona-se com a liberdade de definir o valor do trabalho. Com ela o profissional tem a liberdade de atuar em uma esfera exclusiva de competência. Existem alguns inibidores de autonomia econômica. Um deles é o peso que a estrutura burocrática e institucional pode exercer. Ela pode interferir na organização do trabalho e em sua efetiva realização. Ela pode definir, por exemplo, o ritmo do trabalho, interferindo na autonomia técnica. Ambas as autonomias podem ser limitadas através do poder das associações de consumidores. Elas podem agir no sentido de cobrar maior eficiência ou transparência no exercício de uma determinada atividade, coibindo sua tradicional liberdade. A excessiva competição interna, entre pares, também pode interferir na autonomia do corpo profissional. Finalmente, as precárias condições de trabalho e de remuneração podem impedir que o profissional exerça a plenitude de sua atividade, interferindo nas duas dimensões de autonomia.

Do ponto de vista normativo, o profissional se submete a um longo treinamento, orientado por um currículo padronizado, repleto de etapas e exigências. Durante o período universitário e ao longo de toda a sua atividade, se sujeita aos mecanismos de regulação de conduta, formalizados em um Código de Ética, que visam padronizar sua conduta em três níveis: entre pares, entre estes e seus concorrentes e entre os profissionais e a sociedade. Em geral, as demais atividades do mundo do trabalho prescindem de um código formal que as regule e que padronize sua conduta. Esta padronização tem o objetivo de construir uma imagem positiva do profissional, em seu conjunto, perante os consumidores. Se um profissional agir indevidamente, em um destes três níveis, pode ser punido exemplarmente para que a sociedade continue respeitando a categoria profissional e entenda que foi um gesto isolado. Neste sentido, é criada uma instituição com a finalidade de fiscalizar, coagir e punir os comportamentos desviantes. Esta instituição é o Conselho de Ética. Em geral, ele detém o poder de reconhecer o diploma universitário do recém-formado e de retirar o direito do profissional de continuar exercendo sua atividade. Tal dimensão normativa faz com que as profissões se tornem comunidades com identidade, compromisso pessoal, interesses específicos e lealdade corporativa. Assim, elas conquistam e preservam o prestígio junto à clientela. Com o mesmo intuito, as profissões organizam seus interesses de forma associativa. Por esta razão, elas criam e mantêm sindicatos, clubes, associações culturais, científicas ou por ramo profissional. Por meio de atividades sociais e científicas, promovidas por estas associações, os integrantes da profissão aumentam sua coesão interna, ampliam sua visibilidade social, criam estratégias para impor suas fronteiras profissionais de competência e elegem representantes de seus interesses junto a diferentes instâncias públicas e privadas.

Todo este esforço de nada valerá se a profissão não conseguir convencer a sociedade de sua utilidade. Assim, a profissão se torna imprescindível aos olhos dos consumidores. Para tanto, utiliza-se dos meios de comunicação. Desta forma, a orientação do profissional passa a ser entendida pelo cliente como algo superior a um conselho e inferior a uma ordem. Com o intuito de atingir essa situação, o profissional utiliza-se de meios simbólicos. 0 consumidor de serviços é, portanto, alguém nem muito organizado socialmente nem muito informado. Usando meios persuasivos, o profissional terá melhores condições de impor sua autoridade ao cliente.

0 Estado desempenha um papel decisivo para 0 sucesso de uma profissão. Ele assegura formalmente o monopólio do mercado de trabalho para uma profissão, utilizando, se for necessário, a força policial ou o aparato penal, previstos em Lei. Com isso, ele inibe concorrências desleais e impõe fronteiras de competência. A profissão, por meio de suas associações representativas, procura fazer com que o Estado atenda seus interesses. Para tanto, a profissão organiza-se para eleger seus representantes, fazer com que os eleitos atendam suas demandas e convencer a sociedade da justeza de suas propostas. A literatura especializada enfatiza, ainda, a necessidade de serem levadas em consideração as especificidades de cada atividade profissional (Bonelli ${ }^{18}$ ).

As pesquisas na área da história da profissão de enfermeira poderiam levar em consideração, por exemplo, como o seu conhecimento profissional tornouse complexo, incompreensível por leigos e institucionalizado durante um certo tempo ou em um contexto histórico específico. Outra possibilidade seria verificar as estratégias que as enfermeiras desenvolveram para conquistar e preservar sua autonomia técnica e econômica no mercado de 
trabalho. Os inibidores de autonomia poderiam ser também objeto de interesse histórico na área. A criação das associações profissionais como sindicatos e Conselhos de Ética também poderiam merecer atenção das historiadoras da Enfermagem. Poderia ser verificado, ainda, até que ponto as enfermeiras conseguiram, ao longo de sua história, fazer com que seu Código de Ética normatizasse sua conduta profissional e construísse uma imagem positiva desta profissional. As estratégias de persuasão profissional sobre a sociedade também poderiam compor uma agenda de pesquisa em história da profissão de enfermeira. A intensa relação de tensão e colaboração que se estabelece entre uma profissão e as diferentes instâncias do Estado também são dignas de uma investigação de caráter histórico.

\section{CONSIDERAÇÕES FINAIS}

0 objetivo deste artigo foi apresentar, de forma sumária, alguns elementos presentes no debate historiográfico contemporâneo sobre História da Saúde, da Ciência, das Mulheres e das Profissões que pudessem ser úteis para a escrita da História da Enfermagem: três interfaces. Cada uma delas, a sua maneira, contribui para valorizar esta profissão, pois resgata sua memória e divulga sua história: partes imprescindíveis para a construção da identidade de qualquer profissão. Com isso, pretendemos sugerir que a produção histórica em Enfermagem leve em consideração estas controvérsias historiográficas e se inscreva cada vez mais neste campo, de forma

\section{Referências}

1. Burke P. A Escola dos Annales. 1929-1989. A Revolução Francesa da historiografia Campinas (SP): Ed Universidade Estadual Paulista; 1997.

2. Le Goff J, Nora P. História: novos problemas, novas abordagens, novos objetos. Rio de Janeiro (RJ): Francisco Alves; 1976.

3. Cardoso CF, Vainfas R, organizadores. Domínios da história: ensaios de teoria e metodologia. Rio de Janeiro (RJ):Campus; 1997.

4. Santos Filho LC. História geral da medicina brasileira. São Paulo (SP): HUCITEC; 1977.

5. Foucault M. Nascimento da clínica, São Paulo (SP): Forense; 1963.

6. Machado R, Loureiro A, Luz, R, Muricy K. Danação da norma: medicina social constituição da psiquiatria no Brasil. Rio de Janeiro (RJ): Graal; 1978.

7. Luz MT. Medicina e ordem política brasileira: políticas e instituições de saúde (1850-1930). Rio de Janeiro(RJ): Graal; 1982.

8. Costa JF. Ordem médica e norma familiar. Rio de Janeiro (RJ): Graal; 1989. consciente e qualificada. Poderia ser desenvolvido um outro caminho. Poderia ser analisada a produção historiográfica tradicional em História da Enfermagem para verificar até que ponto ela se inscreve ou não nesta ampla controvérsia historiográfica. Este foi 0 esforço empreendido, por exemplo, por Lusk ${ }^{19}$. Seu objetivo foi descrever os princípios básicos da metodologia histórica, com ênfase na História da Enfermagem. Dois, entre muitos caminhos possíveis, de uma longa caminhada.

Não queremos dizer com este artigo que a produção historiográfica em Enfermagem não esteja inserida no debate sinalizado aqui. São dignos de nota os excelentes artigos, livros, monografias, dissertações, teses e eventos que o 'Núcleo de Pesquisa de História da Enfermagem Brasileira' da Escola Anna Nery da Universidade Federal do Rio de Janeiro vem produzindo nos últimos anos. Além disso, este Núcleo também tem formado gerações de enfermeiras com sensibilidade histórica. Este esforço não deve ser negligenciado.

Apresentamos neste artigo uma agenda potencial de pesquisa. Esta palavra teve para nós, neste artigo, duas dimensões. Potencial, pois revela algumas possibilidades, e não todas, de realização de pesquisa. E potencial, pois sugere uma agenda de pesquisa grande, forte e poderosa. Pesquisas na área da História da Enfermagem, que, de uma forma ou de outra, se inscrevam no amplo debate historiográfico sinalizado neste artigo, têm todas as condições de compartilhar das mesmas preocupações que a comunidade de historiadores da saúde compartilha nos dias de hoje no Brasil, como em outras partes do mundo.

9. Latour B. Ciência em ação: como seguir cientistas e engenheiros sociedade afora. São Paulo (SP): UNESP; 1999.

10. Kuhn T. A estrutura das revoluções científicas. São Paulo(SP): Perspectiva; 1996.

11. Schwartzman S. Formação da comunidade científica no Brasil. Rio de Janeiro (RJ): FINEP; 1979.

12. Roberts B. Biographical research: understanding social research. Buckingham (UK): Open University Press; 2002.

13. Duby G, Perrot M. L'histoire des femmes en o0ccident de I'antiquité à nos jours, Paris(FR): Plon; 1991/1992. 5v.

14. Bresciani MSM As mulheres no espaço público. São Paulo (SP): ANPUH/Marco Zero; 1989.

15. DelPriori M. História das mulheres no Brasil. São Paulo (SP):Contexto; 1999.

16. Freidson E. Profession of medicine: a study of the sociology of applied knowledge. New York (NY): Harper and Row; 1970.

17. Barbosa MLO. As profissões no Brasil e sua sociologia. Dados 2003 jul; 46(3): 593-07. 
18. Bonelli MG. Estudos sobre profissões no Brasil In: Miceli S, organizador. 0 que ler na ciência social brasileira (1970-1995) São Paulo (SP): Sumaré/anpocs; Brasília (DF): CAPES; 2002.

19. Lusk B. Historical methodology for nursing research. J Nurs Scholarship, 1997; 29(4): 355-59.

\section{Sobre o Autor}

\section{André de Faria Pereira Neto}

Historiador, Doutor em Saúde Coletiva, Pesquisador Titular da Casa de Oswaldo Cruz - Fundação Oswaldo Cruz (apereira@fiocruz.br). 